\title{
PROTECTIVE ROLE OF SPHAERANTHUS AMARANTHOIDES EXTRACT ON DERMAL WOUNDS IN WISTAR RATS
}

\author{
${ }^{1}$ L.Swarna Latha, ${ }^{2}$ P.Neelakanta Reddy ${ }^{3}$ Dr.Kanchana Amarnath \\ ${ }^{1}$ Research Scholar, Department of Biotechnology, Sathyabama University, Chennai \\ ${ }^{2}$ Scientist \& Head, Department of Bio-organic Chemistry Laboratory, CLRI, Adayar, Chennai \\ ${ }^{3}$ Senior Lecturer, Dept.of Bio-Technology,Sathyabama University \\ Email : drylcphd@gmail.com
}

\begin{abstract}
The healing potential of ethanolic extract of aerial parts of Sphaeranthus amaranthoides, Linn. (Asteraceae) (SAE) for treatment of dermal wounds in wistar rats was studied on excision wound models. Various parameters studied are epithelization and wound contraction. The extract was applied in thedorsal thoracic region of six excised wounded models once in a day for 16 days. The results obtained indicate that Sphaeranthus amaranthoides accelerates the wound healing process by decreasing the surface area of wound. Framycetin sulphate was used as positive control complete epithelization was observed within 16 days with Sphaeranthus amaranthoides The extract significantly enhanced the rate of wound contraction and the period of epithelialization comparable to framycetin sulfate.
\end{abstract}

KEYWORDS: Sphaeranthus amaranthoides; Asteraceae; Wound contraction; Epithelialization; framycetin sulfate.

\section{INTRODUCTION}

Wound is a contravene in the normal tissue continuum, resulting in a variety of cellular and molecular sequelae. The basic principles of optimal wound healing which include minimizing tissue damage, debriding nonviable tissue, maximizing tissue perfusion and oxygenation, proper nutrition and moist wound healing environment have been recognized for many years (1). Wound healing results in contraction and closure of the wound and restoration of a functional barrier (2). Tissue repair and cutaneous wound healing are the complex processes that involve a series of biochemical and cellular reactions, beginning with inflammation and followed by the repair and remodeling of the injured tissue (3). Granulation, collagen maturation and scar formation are some of the many phases of wound healing which run concurrently, but independent of each other (4). During inflammatory phase, macrophage is referred to as orchestrate for the removal of fibrin and proliferation of fibroblast, is also responsible for the secretion of TNF and TGF that stimulate fibroblast and keratinocytes, respectively (5). In the last maturational phase, wound undergoes contraction resulting in reduction of size of apparent scar tissue, as wound contraction is the process of mobilizing healthy skin surrounding the wound to cover the denuded area. This centripetal movement of wound margin is believed to be due to the activity of myofibroblast (6).

A number of drugs ranging from simple nonexpensive analgesics to complex and expensive chemotherapeutic agents administered in the management of wound affect healing either positively or negatively (7). India has a rich flora that is widely distributed throughout the country and the search for natural remedies for healing has drawn attention to medicinal species.. Several plant species are used by many ethnic groups for the treatment of various ailments ranging from minor infections to dysentery, skin diseases, asthma, malaria and a horde of other indications. Majority of world's population relies on traditional medicines for the treatment of wounds. In developing countries, remedies prepared from herbal extract have been widely used in the treatment of wounds. Plants such as Physic nut (8), St. John's Wort (9), Aloes (10), Red sandal wood (11) and Cinnamon (12) have been found effective in treating dermal wounds on different wound models.

$S A E$ and its species are widely distributed in tropical Asia, Africa and Australia. All the species of this plant possess medicinal uses and have been reported to have beneficial effects on several ailments. The juice of the plant is styptic and diuretic and it is said to be useful against liver and gastric disorders. Roots and seeds are used as stomachic and anti-helminthic. It has been reported that flowers of this species are highly alterative, depurative, cooling and tonic. They are also used as blood purifiers in skin diseases (13). Dried and powdered leaves of Sphaeranthus amarqanthoides are useful in the treatment of chronic skin diseases, urethral discharges and jaundice (14). Extract of Sphaeranthus amaranthoides has been reported to exhibit excellent antibacterial activity against Gram positive as well as Gram negative bacteria. The phytochemical analysis of the plant showed that it contains steroids, triterpenoids, phenolic compound, flavonoids, tannins and glycosides (15). In recent years oxidative stress (Reactive oxygen Species) has been implicated as deleterious in a variety of degenerative process and diseases. These include acute and chronic inflammatory condition such as wound healing (16). These conditions are difficult to manage due to high cost of therapy and side effects. Topical application of compounds with Ros scavenging activity in patients have shown to recover significantly wound healing and to protect tissues from 
oxidative damage (16). Polyphenolic bioflavonoide (tannins and flvanoids) synthesized by many plants facilitate wound healing (17). It is evident that the role of free radicals in the physiology of wound is clearly defined and the plant is examined to contain these phyto chemicals with potent antioxidant activity. In view of all the pharmacological activities of different species of sphaeranthus and the phytochemical constituents, its utilization in the treatment of skin diseases (13), present study has been studied for the wound healing effect of SAE.

\section{MATERIALS AND METHODS}

\subsection{Preparation of extract}

Aerial parts of dried plant were purchased from local market and identified by plant taxonomist, Department of Botany, Anna Hospital, Chennai, Tamilnadu, and South India. Aerial parts of Sphaeranthus amaranthoides (3 kg) were extracted three times with $95 \%$ ethanol at room temperature. Extracts obtained were combined and evaporated on Rota vapor under reduced pressure to give a residue $(118 \mathrm{~g})$.

\subsection{Animals and drugs}

Male Wistar rats were obtained from Kings Institute,Guindy,Chennai. They were kept in the animal house at relative humidity, 44-45\%, light and dark cycles of 10 and $14 \mathrm{~h}$, respectively, one week before the experiment. Animals were fed with sterile food (M/s Hindustan Liver Ltd.) and water ad libitum.

\subsection{Excision wound model}

Male wistar rats were divided into three groups of six animals in each group. Groups I-III were treated as control, standard, SAE respectively. The animals were depilated on the thoracic region prior to creation of wounds and a predetermined area of $250-300 \mathrm{~mm}^{2}$; skin in its full thickness was excised under ether anesthesia. Wounds were dressed once daily for 15 days i.e. group I treated as control, group II treated with the standard drug framycetin sulphate cream ointment and group III treated with ethanolic extract respectively. The animals were maintained individually in separate cages.

\subsection{Measurement of wound area}

The progressive changes in wound area were measured in $\mathrm{mm}^{2}$ by tracing the wound boundaries around it on a transparent paper on every alternate day. Wound contraction was expressed as percentage reduction of original wound size.

\subsection{Statistical analysis}

The data are expressed as mean ü S.E.M. using analysis of variance followed by Student's t-test. Significance is calculated by comparing percentage of wound contraction in group-1 (Control) against group-II (treated with framycetin sulphate); group-III (treated with extract) versus group-II; and also group-l against group-III. The value of $p$ $<0.001$ were considered significant. The percentage of wound contraction was calculated as a percentage of the corresponding 0 day's (original) wound area $\left(\mathrm{mm}^{2}\right)$.

\section{RESULTS \& DISCUSSION}

LD50 of SAE was found to be $500 \mathrm{mg} / \mathrm{kg} \mathrm{b.w} 1 / 10^{\text {th }}$ of the dose was selected for evaluating wound healing activity i.e $50 \mathrm{mg} / \mathrm{kg}$ b.w. The progress of wound healing induced by SAE, framycetin sulphate and control on wistar rats are shown in Table- 1 and Pictures 1, 2, 3. Time for wound closure as well as for falling of scar by extract, control and framycetin sulphate are comparable and extract showed effective healing percentage (100\%) after 15 days treatment. However, when percentage of wound healing was compared between group-I and group-II; group-II versus group- III; and group-I against group-III, significance was found only in group-l (treated with extract) versus group-II (control). Significant difference in percentage of healing was observed from 2nd to 12th days of application (vide Table-1) and maximum difference was recorded after 6th and 8 th days of treatment as $44.3 \%$ versus $25.2 \%$; and $99.8 \%$ versus $88.7 \%$, respectively. It may therefore be concluded that under present working condition SAE has been determined as most active healing agent.

The present study therefore reveals that $S A E$ enhanced wound contraction (Picture 3 ) significantly. This would have either enhanced contractile property of myofibroblasts or increased the number of myofibroblasts recruited into the wound area, and may also be due to collagen which is a major protein for the extra cellular matrix that ultimately contributes to wound strength (18).

\section{Picture:1:0 $0^{\text {th }}$ Day:}

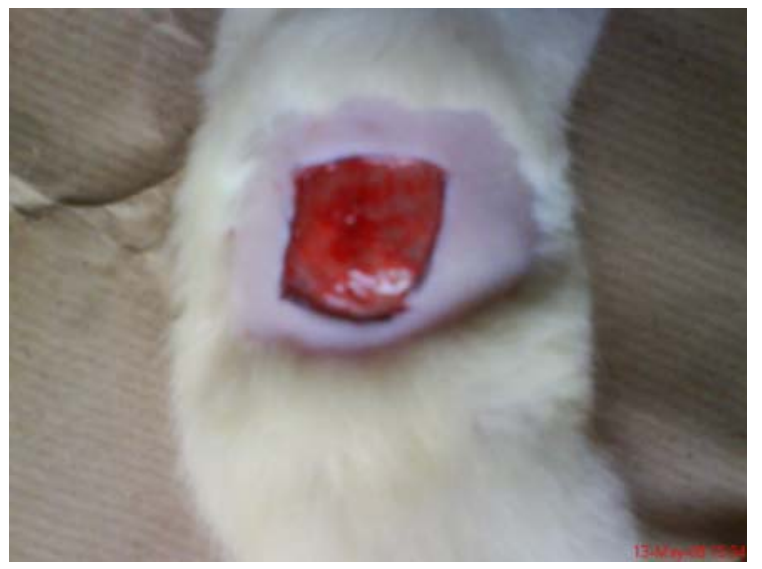




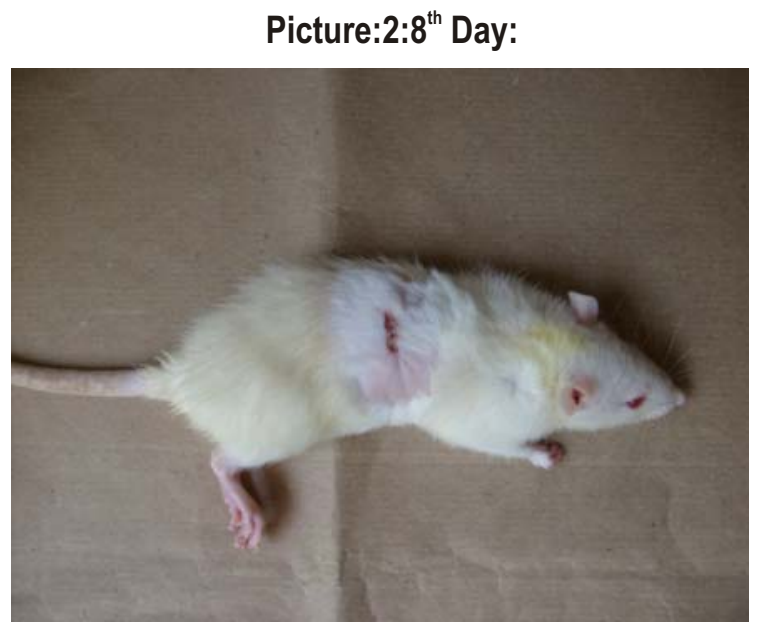

Picture:3:14 ${ }^{\text {th }}$ Day:

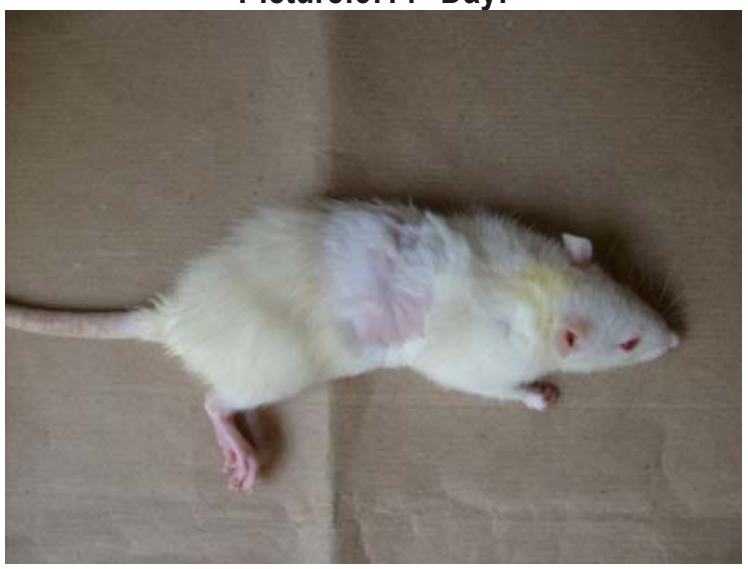

This enhanced wound contraction effect of $S A E$ and epithelialization could possibly be made use clinically in healing of open wounds. However confirmation of this suggestion will need well-designed clinical evaluation. The wound healing effect performed in guinea pigs using Sphaeranthus indicus (19) there fore justifies the folkloric use of $S A E$ to treat skin diseases. However, in order to unravel the possible mechanism involved in the process of wound healing either by regulating body's defensive mechanism or by direct action of drug on wound, more work is required.

Table 1. Wound healing potency of Sphaeranthus amaranthoides

\begin{tabular}{|c|c|c|c|}
\hline Post healing days & Control & Framycetin sulphate & $S A E$ \\
\hline 0 & $272 u ̈ 26.3$ & 260 ü25.8 & 250 ü25.2 \\
\hline 2 & 257.14ü22.8(5.2) * & 239.2ü26.4(8.2) & 219.50ü21.4(12.2) \\
\hline 4 & $237.26 u ̈ 21.3(12.6)$ ** & 223.8ü22.1(14.3) & 183.5ü19.3(26.6) \\
\hline 6 & 214.70ü20.2(21.3) * & 194.48ü18.6(25.2) & 139.25ü14.6(44.3) \\
\hline 8 & 189.43ü18.1(30.4) *** & $150.02 u ̈ 16.2(42.3)$ & 83.17ü8.7(66.8) \\
\hline 10 & 158.54ü14.7(41.6) *** & 89.96ü11.7(65.4) & 26.25ü3.1(89.5) \\
\hline 12 & 126.45ü12.6(53.5) *** & 29.38ü5.8(88.7) & 2.75ü0.21(99.8) \\
\hline 14 & 90.72ü3.4(66.7) & 2.86ü1.3(98.9) & $1.43 u ̈ 0.01(100)$ \\
\hline 16 & 65.01ü0.03(75.8) & 0.50 ü0.02(100) & \\
\hline
\end{tabular}

Significance is calculated by comparing $\%$ of wound contraction in group-I against group-II; group-III vs. groupII; and also group-l against group-III.

${ }^{*} P<0.02 .{ }^{* *} P<0.05$. ${ }^{* * *} P<0.001 .{ }^{* * *} P<0.01$.

\section{REFERENCES}

[1] Pierce GF, Mustoe TA. Pharmacologic enhancement of wound healing. Annu Rev Med1995; 46: 467-481.

[2] D. Chattopadhyay, G. Arunachalam, A. B. Mandal, T. K. Sur, S. C. Mandal and S. K. Bhattacharya, Antimicrobial and anti-inflammatory activity of folklore: Mellotus peltatus leaf extract, J. Ethnopharmacol. 82 (2002) 229-237.

[3] G. D. Phillips, R. A. Whitehe and R. Kinghton, Initiation and pattern of angiogenesis in wound healing in the rat, Amer. J. Anat. 192 (1991) 257-262.

[4] G. S. Sidhu, H. Mani, J. P. Gaddipatti, A. K. Singh, P. Seth, K. K. Banaudha, G. K. Patnaik and R. K. Maheshwari, Curcumin enhances wound healing in streptozotocin induced diabetic rats and genetically diabetic mice, Wound Repair Regen. 7 (1999) 362-374.

[5] Gabbaiani G, Harschel BJ, Ryan GB. Granulation tissue as a contractile organ. J Exp Med 1976; 135: 719.

[6] Shanbhag Tara V., Sharma Chandrakala, Adiga Sachidananda, Bairy Laxminarayana Kurady*, Shenoy SmitaAnd Shenoy Ganesh Wound Healing

[7] Prasad D, Rao CM. Wound healing profile of ketorolac, metronidazole and tinidazole administered postsurgically. Ind J Exp Biol 1995;33: 845-84

[8] Villegas, L.F., Fernandez, I.D., Maldonado, H., Torres, R., Zavaleta, A., Vaisberg, A.J., Hammond, G.B., 1997. Evaluation of the wound healing activity of selected traditional medicinal plants from Per A? Journal of Ethno pharmacology 55, 193-200.

[9] Upton, R., 1997. American Herbal Pharmacopoeia and Therapeutic Compendium St. John's Wort Monograph. American Herbal Pharmacopoeia, Santacruz, CA, pp. 3-13.

[10] Davis, R.H., Donato, J.J., Hartman, G.M., Haas, R.C., 1994. Anti-inflammatory and wound healing activity of a growth substance in Aloe vera. Journal of the American Podiatric Medical Association 84, $77-81$. 
[11] Biswas, T.K., Maity, L.N., Mukherjee, B., 2004. Wound healing potential of Pterocarpus Santalinnus Linn.: a pharmacological evaluation. The International Journal of Lower Extremity Wounds 3, 143-150.

[12] Kamath, J.V., Rana, A.C., Chowdhury, A.R., 2003. Pro-healing effect of Cinnamomum zeylanicum bark. Phytotherapy Research 17, 970-972.

[13] Kirtikar, K.R., Basu, B.D., 1918. Indian Medicinal Plants. Published by Lalit Mohan Basu, Allahabad, India, pp. 1-2.

[14] Nadkarni, K.M., 1976. Indian Materia Medica, 1. Published by Popular Prekashan, Bombay, p. 1162.
[15] Antimicrobial Antidiahorreal And Phytochemical Activities Of Spheranthus Amaranthoides Indian Jornal Of Pharmacology (Communicated)

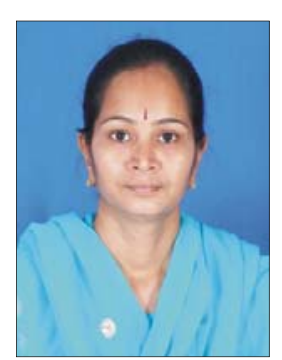

Mrs..Swarna Latha.L is a Lecturer in the Department of Bio-Technology ,Sathyabama University, Chennai600119, doing her Doctoral Research under the guidance and supervision of Dr.P.Neelakanta Reddy, Scientist and Head, Bio-organic chemical Laboratory, CLRI,Chennai-30. Her area of expertise is Micro-Biology and Bio-Chemistry. 